\title{
A CLINICAL STUDY ON OBSTRUCTIVE JAUNDICE
}

\author{
Paatneedi Naresh Kumar1, Ravula Maha Lakshmi2, Gonugunta Sri Ranga Sai Karthik ${ }^{3}$
}

${ }^{1}$ Associate Professor, Department of General Surgery, Rangaraya medical College, Kakinada.

2Professor, Department of General Surgery, Rangaraya Medical College, Kakinada.

${ }^{3}$ Postgraduate Student, Department of General Surgery, Rangaraya Medical College, Kakinada.

\section{ABSTRACT}

\section{BACKGROUND}

Jaundice refers to yellowish discolouration of skin, sclera and mucous membranes due to increased concentration of bilirubin in body fluids. The pathological mechanism of jaundice can be classified into haemolytic, hepatocellular and obstructive. Jaundice that can be corrected with surgery is known as obstructive jaundice.

Aims

- To study the cases of obstructive jaundice and evaluation of clinical features, diagnosis and management.

- To study incidence in relation to age and sex of patients.

- To study various causes, pathological diagnosis in obstructive jaundice cases.

- To study the clinical presentation in various surgical jaundice patients.

- To study the treatment in various surgical jaundice patients.

\section{MATERIALS AND METHODS}

A prospective study was conducted at Government General Hospital, Kakinada. The study period was from August 2010 - August 2013. The study sample constituted 30 patients. Inclusion criteria - All patients admitted and diagnosed to have obstructive pattern of jaundice.

\section{RESULTS}

Most common cause of surgical jaundice is CBD calculi. Most common presentation is jaundice followed by loss of weight and loss of appetite. In benign causes, most common presentation is pain abdomen followed by jaundice.

\section{CONCLUSION}

In benign cases, the common symptom is pain abdomen and next is jaundice. In malignant cases, most common symptom is jaundice and next is loss of weight and appetite. There was significant high value of total bilirubin, direct bilirubin, alkaline phosphatase in malignant condition. Decreased value of albumin and altered coagulation profile seen in malignancy. ERCP is comparatively as good modality of treatment as open exploration of CBD in management of CBD calculi. In malignancy, early detection, staging, selection of patients are important to get benefit from curative resection; whereas in those not suitable for curative resection, good improvement in quality of life has been shown by palliative procedures.

\section{KEYWORDS}

Age and Sex Incidence, Clinical Presentation, Management Strategies and Followup, Diagnostic and Therapeutic ERCP.

HOW TO CITE THIS ARTICLE: Kumar PN, Lakshmi RM, Karthik GSRS. A clinical study on obstructive jaundice. J. Evolution Med. Dent. Sci. 2016;5(101):7444-7447, DOI: 10.14260/Jemds/2016/1685

\section{BACKGROUND}

Jaundice refers to yellowish discoloration of skin, sclera and mucous membranes due to increased concentration of bilirubin in body fluids. The pathological mechanism of jaundice can be classified into haemolytic, hepatocellular and obstructive. Though surgical jaundice can be distinguished from medical jaundice by thorough history, examination and simple investigations they provide little or even misleading information about the site of obstruction and its cause. Recent advances in imaging techniques and innovative techniques for access of biliary tract helps a lot in diagnosis. Cholestasis was coined by Berg and has replaced the older term obstructive jaundice.

Financial or Other, Competing Interest: None.

Submission 14-10-2016, Peer Review 07-12-2016,

Acceptance 13-12-2016, Published 19-12-2016.

Corresponding Author:

Dr. Paatneedi Naresh Kumar,

\#10-5-27/1, Nageswar Rao Street,

Ramaraopeta, Kakinada,

Andhra Pradesh.

E-mail:drnaresh180532@yahoo.com

DOI: $10.14260 /$ jemds $/ 2016 / 1685$
It occurs when there is an obstruction to the passage of conjugated bilirubin from liver cells to intestine. ${ }^{1}$ Cholestasis may be due to intrahepatic disease, which is rarely amenable to surgical treatment or due to extrahepatic disease which is amenable to surgical management. The later one is called surgical jaundice and is the main concern in the study. To diagnose the point of obstruction and management of cause of jaundice is indeed a challenging task for surgeon, ${ }^{2}$ hence a detailed study on aetiology, site of obstruction and management is done. Precise diagnosis and early management of obstructive jaundice is needed as obstruction if unrelieved can cause secondary biliary cirrhosis. ${ }^{3}$

\section{Present Study}

A prospective study was taken up in the period of August 2010 to August 2013 and a study population of 30 patients were included in the study. The protocol was approved by the local ethics committee and written informed consent was obtained from each patient.

\section{RESULTS}

- A total of 30 cases of obstructive jaundice were studied. 
- Peak age group was 31-70 years with Male:Female = 46.7:53.3\% with slight female preponderance.

\begin{tabular}{|c|c|c|}
\hline AGE & No. of Patients & Percentage \\
\hline$<30$ & 4 & $13.33 \%$ \\
\hline $31-40$ & 7 & $23.33 \%$ \\
\hline $41-50$ & 7 & $23.33 \%$ \\
\hline $51-60$ & 7 & $23.33 \%$ \\
\hline $61-70$ & 5 & $16.64 \%$ \\
\hline
\end{tabular}

- It is caused by both benign and malignant conditions. ${ }^{4}$

- The benign cases reported in this study were 19 of which 14 cases were due to choledocholithiasis, 3 cases were due to benign strictures, 2 cases were choledochal cysts. The malignant cases identified were 11 in which 6 cases were carcinoma head of pancreas, 3 were cholangiocarcinoma and remaining 2 were due to periampullary carcinoma.

- Most common cause is choledocholithiasis.
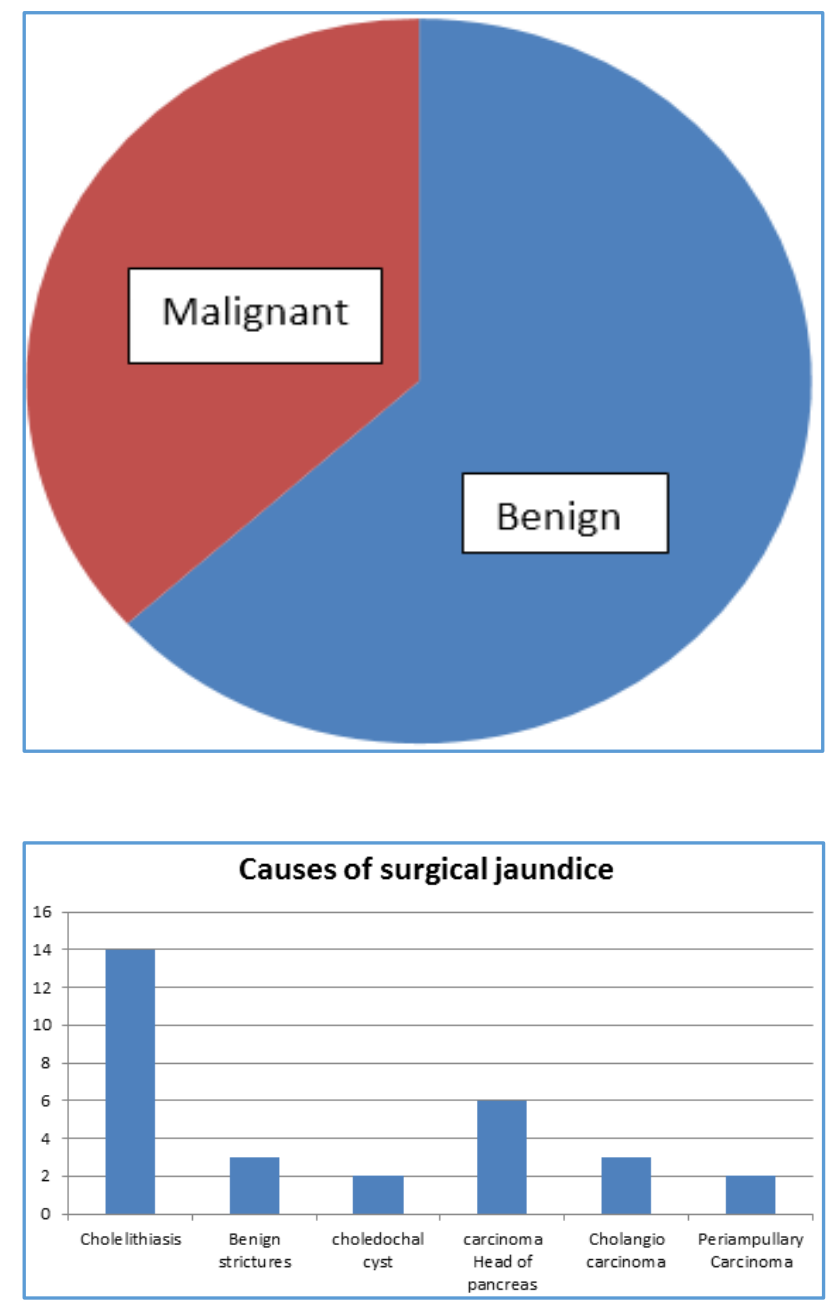

- Most common presentations are jaundice and pain. In benign cases, common symptom is pain (89.4) and next is jaundice (84.2). In malignant surgical jaundice, the most common symptom is jaundice (90.9) and next is loss of appetite and weight (81.4).

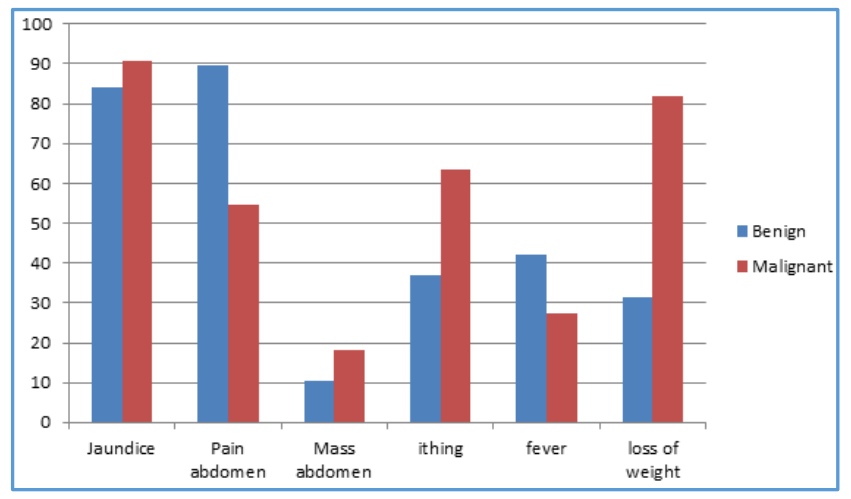

- Raised bilirubin, alkaline phosphatase and decreased albumin were more pronounced in malignancy.

- USG is the cheapest and noninvasive procedure in diagnosis of obstructive jaundice and more effective in diagnosing distended CBD, dilated IHBRD and distended gall bladder.

- Recently, increasing reliance on ERCP and MRCP to image biliary tree has helped to diagnose the pathology earlier and hence early intervention can be initiated.

- For CBD calculi most of them underwent open CBD exploration with cholecystectomy and others underwent ERCP sphincterotomy with stone extraction. When both were compared the success rate and morbidity showed no difference.

- For malignant causes, curative procedures (Whipple) and palliative drainage procedures (cholecystojejunostomy) were done.

- Two patients expired on 4 th and $7^{\text {th }}$ postoperative day respectively due to peritubal leakage and cholangitis and one patient expired due to advanced metastatic disease after 2 months during 6 months of followup.

\section{DISCUSSION}

Obstructive jaundice patients admitted in GGH - 30 .

\section{Age Incidence}

The peak incidence was between 31-70 yrs. Out of the 30 cases studied, 21 were from this age (70\%). The mean age was 47 yrs. The age of benign disease cases was 22-65 yrs. and age of malignant cases was 38-66 yrs.

\section{Sex Incidence}

Affected male patients were 14 out of $30(46.7 \%)$ and females were 16 (53.3\%) with slight female predominance.

In the 30 cases of study, 19 cases were due to benign causes of which most common was choledocholithiasis in 14 cases (46.67), remaining cases were benign stricture in 3 (10\%) and choledochal cyst in 2 (6.67\%). Benign causes are more common as in study done by Bekele et al. ${ }^{5}$ 


\begin{tabular}{|c|c|c|c|c|}
\hline Study & $\begin{array}{c}\text { Pellagrene et al } \\
\mathbf{( 1 9 8 2 )}\end{array}$ & $\begin{array}{c}\text { JA Pain et al } \\
\mathbf{( 1 9 8 7 )}\end{array}$ & $\begin{array}{c}\text { Parks RW } \\
\text { (1997) }\end{array}$ & Present study \\
\hline No. of cases & 178 & 30 & 121 & 30 \\
\hline Ca HOP & $36(20.02 \%)$ & $13(43.3 \%)$ & $42(34.7 \%)$ & $6(20 \%)$ \\
\hline Periampullary & - & - & $2(1.7 \%)$ & $2(6.67 \%)$ \\
\hline Cholangiocarcinoma & $29(16.3 \%)$ & $1(3.3 \%)$ & $12(9.9 \%)$ & $3(10 \%)$ \\
\hline Choledocholithiasis & $46(25.8 \%)$ & $14(46.7 \%)$ & $25(20.7 \%)$ & $14(46.7 \%)$ \\
\hline Benign stricture & $49(27.5 \%)$ & - & $5(4 \%)$ & $3(10 \%)$ \\
\hline
\end{tabular}

The malignant causes were in $11(36.6 \%)$ cases. Carcinoma head of pancreas $6(20 \%)$, cholangiocarcinoma in $3(10 \%)$ cases and periampullary in $2(6.67 \%)$ cases, contrary to the study done by Sharm and Ahuj in which carcinoma gall bladder was the common cause of malignant obstructive jaundice. ${ }^{6}$ Carcinoma head of pancreas was the most common malignant cause of obstructive jaundice whereas choledocholithiasis was the most common benign cause, and is comparable with other studies ${ }^{7,8,9}$.

Jaundice was present in 26 patients $(86.67 \%)$ and in malignancy it was $90.9 \%$.

Pain abdomen was present in 23 (76.66\%). In benign cases, it was $89.4 \%$ and in malignant it was $54.54 \%$, mostly pain was felt in Rt. hypochondrium and epigastrium.
High coloured urine was present in 17 patients (56.66\%). In benign conditions, it was $52.63 \%$ and in malignant conditions it was $63.63 \%$.

Itching was present in 14 cases (46.66\%). In benign conditions, it was $36.84 \%$ and in malignant conditions it was $63.63 \%$.

Clay coloured stool was present in 14 patients (46.66\%). In benign $36.48 \%$ and in malignant $63.63 \%$.

Loss of weight and loss of appetite was present in 15 cases (50\%), in benign $31.57 \%$ and in malignant $81.81 \%$.

In benign conditions, the most common symptom is pain abdomen (89.4\%) and next is jaundice (84.2\%). In malignant cases most common symptom is jaundice (90.91\%) and next is loss of weight and loss of appetite (81.81\%).

\begin{tabular}{|c|c|c|c|c|c|}
\hline Study & Jaundice & Pain abdomen & Loss of weight & Mass abdomen & Pruritis \\
\hline Warren et al (1983) & 75.90 & 82.80 & 90 & 16.70 & 41.30 \\
\hline Brook et al (1981) & $77 \%$ & $51 \%$ & $55 \%$ & $18 \%$ & - \\
\hline Van Wagensveld BA et al & $90 \%$ & $60 \%$ & $82 \%$ & - & - \\
\hline Present study & $86.67 \%$ & $76.66 \%$ & $50 \%$ & $13.33 \%$ & $46.66 \%$ \\
\hline
\end{tabular}

In the present study, total bilirubin in benign cases varied from $1.2-18.4 \mathrm{mg} / \mathrm{dL}$ with mean value of 6.12 and in malignant cases $1.4 \mathrm{mg} / \mathrm{dL}$ to $17.8 \mathrm{mg} / \mathrm{dL}$ with mean value 10.31 .

Out of the 11 cases of malignancy, ALP varied from 84 IU to 912 IU with mean value of 306.18 and in 19 benign cases the mean value is 270.57 .

\begin{tabular}{|c|c|c|c|}
\hline Parameter & $\begin{array}{c}\text { Benign (n=19) } \\
\text { mean } \pm \text { SD }\end{array}$ & $\begin{array}{c}\text { Malignant (n=11) } \\
\text { Mean } \pm \text { SD }\end{array}$ & $\begin{array}{c}\text { Total (n=30) } \\
\text { mean } \pm \text { SD }\end{array}$ \\
\hline Hb\% (g/dL) & $10.7 \pm 1.242$ & $8.56 \pm 1.42$ & $10.2 \pm 1.57$ \\
\hline Total bilirubin (mg/dL) & $6.12 \pm 4.67$ & $10.2 \pm 1.57$ & $7.66 \pm 5.33$ \\
\hline Direct bilirubin (mg/dL) & $3.52 \pm 3.14$ & $7.01 \pm 4.04$ & $4.8 \pm 3.834$ \\
\hline AST(SGOT) (IU/dL) & $83.57 \pm 47.94$ & $115.09 \pm 55.49$ & $95.133 \pm 52.22$ \\
\hline ALT(SGPT) (IU/dL) & $81.52 \pm 46.1$ & $143.18 \pm 122.8$ & $104.13 \pm 86.23$ \\
\hline ALP (IU/dL) & $270.57 \pm 216.7$ & $306.18 \pm 243.1$ & $283.63 \pm 223.2$ \\
\hline Prothrombin time (sec) & $14.2 \pm 2.02$ & $15.5 \pm 1.86$ & $14.7 \pm 2.033$ \\
\hline Albumin (g) & $3.33 \pm 0.53$ & $2.67 \pm 0.42$ & $3.09 \pm 0.58$ \\
\hline
\end{tabular}

There were significant high values of total bilirubin, direct bilirubin and alkaline phosphatase in malignant conditions and decreased values of albumin and alteration in coagulation profile was also found in malignant conditions.

USG was used as a standard imaging technique for evaluation of causes of jaundice in this is study with accuracy regarding site of obstruction nearly in 28 (93\%).
Prothrombin time had a mean value of $14.2 \mathrm{sec}$ in benign and $15.5 \mathrm{sec}$ in malignant cases.
Preoperative biliary drainage was considered as jaundice increases the perioperative complications. So to decrease the complications of surgery in jaundiced patients, preoperative biliary drainage was considered before curative resection. ${ }^{10}$ Though early studies showed decreased morbidity, ${ }^{11}$ the more recent studies have shown deleterious effects of preoperative biliary drainage such as increased infectious complications and operative mortality. ${ }^{12}$ 
Operative Procedures

\begin{tabular}{|c|c|c|}
\hline Procedure & $\begin{array}{c}\text { No. of } \\
\text { Cases }\end{array}$ & $\mathbf{\%}$ \\
\hline $\begin{array}{c}\text { Cholecystectomy, CBD exploration and } \\
\text { 'T'tube drainage }\end{array}$ & 10 & 33.33 \\
\hline $\begin{array}{c}\text { ERCP sphincterotomy, stone extraction, } \\
\text { stent drainage }\end{array}$ & 4 & 33.33 \\
\hline Whipple procedure & 4 & 13.33 \\
\hline $\begin{array}{c}\text { Hepaticojejunostomy (Roux-en-Y } \\
\text { procedure) }\end{array}$ & 2 & 6.67 \\
\hline $\begin{array}{c}\text { Choledochojejunostomy and } \\
\text { Jejunojejunostomy }\end{array}$ & 1 & 3.33 \\
\hline $\begin{array}{c}\text { Cholecystojejunostomy, } \\
\text { Jejunojejunostomy } \pm \\
\text { Gastrojejunostomy }\end{array}$ & 5 & 16.67 \\
\hline ERCP sphincterotomy and Stent & 4 & 13.33 \\
\hline
\end{tabular}

\section{Complications}

\begin{tabular}{|c|c|c|}
\hline Complication & $\begin{array}{c}\text { No. of } \\
\text { Cases }\end{array}$ & Percentage \\
\hline Peritubal leak with cholangitis & 5 & 16.67 \\
\hline Right pleural effusion & 1 & 3.33 \\
\hline $\begin{array}{c}\text { Wound dehiscence \& } \\
\text { secondary suturing }\end{array}$ & 2 & 6.67 \\
\hline Death & 2 & 6.67 \\
\hline
\end{tabular}

\section{CONCLUSION}

From this study of 30 cases of surgical jaundice, following can be concluded:

- Most common presentation of surgical jaundice is jaundice followed by pain abdomen.

- Most common age group is 31-70 and sex ratio M:F $=1: 1.14$.

- Most common cause is CBD calculus.

- In benign cases, the common symptom is pain abdomen and next is jaundice. In malignant cases, most common symptom is jaundice and next is loss of weight and appetite.

- There was significant high value of total bilirubin, direct bilirubin, alkaline phosphatase in malignant condition, decreased value of albumin and altered coagulation profile in malignancy.

- Most cases of malignancy had history of high coloured urine with clay coloured stools with itching when compared to benign condition. Loss of weight and appetite were more pronounced in malignancy.

- USG remains cheapest, safest and most reliable diagnostic tool in management of surgical jaundice.
- ERCP has both therapeutic and diagnostic advantages over MRCP which is only diagnostic.

- ERCP is comparatively as good modality of treatment as open exploration of CBD in management of CBD calculi.

- In malignancy, early detection, staging, selection of patients are important to get benefit from curative resection, whereas in those not suitable for curative resection, good improvement in quality of life has been shown by palliative procedures.

- Early diagnosis and management helps to reduce the mortality and morbidity rates.

\section{REFERENCES}

1. Mohamed S, Syed AI. Management of obstructive jaundice: experience in a tertiary care surgical unit. Pakistan Journal of Surgery 2007;23(1):23-5.

2. Ahmad I, Jan AU, Ahmad R. Obstructive jaundice. J Postgrad Med Inst 2001;15:194-8.

3. Briggs CD, Peterson M. Investigation and management of obstructive jaundice. Surgery 2007;25(2):74-80.

4. Roche SP, Kobos R. Jaundice in the adult patient. American Family Physician 2004;69(2):299-304.

5. Bekele Z, Yifru A. Obstructive jaundice in adult Ethiopians in a referral hospital. Ethiop Med J 2000;38(4):267-75.

6. Sharma MP, Ahuja V. Aetiological spectrum of obstructive jaundice and the diagnostic ability of ultrasonography: a clinician's perspective. Trop Gastroenterol 1999;20(4):167-9.

7. Khurram S, Qasim A, Shirin M, et al. Evaluation of the aetiological spectrum of obstructive jaundice. J Ayub Med Coll Abbottabad 2008;20(4):62-6.

8. Syed N, Mohammad SA, Umair UI, et al. Etiological spectrum of obstructive jaundice. Medical Channel 2010;16:299-301.

9. Lawal D, Oluwole S, Makanjuola D, et al. Diagnosis, management and prognosis of obstructive jaundice in IleIfe, Nigeria. West Afr J Med 1998;17(4):255-60.

10. Van der Gaag NA, de Castro SM, Rauws EA, et al. Preoperative biliary drainage for periampullary tumors causing obstructive jaundice; Drainage vs. (direct) operation (DROP-trial). BMC Surg 2007;7:3.

11. Nakayama $T$, Ikeda A, Okuda K. Percutaneous transhepatic drainage of the biliary tract technique and results in 104 cases. Gastroenterology 1978;74(3):554-9.

12. Van der Gaag NA, Kloek JJ, de Castro SM, et al. Preoperative biliary drainage in patients with obstructive jaundice: history and current status. J Gastrointest Surg 2009;13(4):814-20. 